\title{
CALIDAD DE LA MEDIACIÓN FAMILIAR LICITADA: SUPERANDO EL MODELO EXPRESS
}

Quality of family mediation tendered: surpassing the express model.

Adriana Palavecino Cáceres ${ }^{1}$

Fecha de Recepción: 30/09/2011

Fecha de Aceptación: 11/11/2011

\begin{abstract}
Resumen
Este artículo aborda la actual situación de los servicios de mediación familiar licitada constatando que se ha instalado un modelo express de dudosa calidad que no logra plasmar debidamente los principios que rigen esta disciplina y que privilegia el acuerdo sin importar cómo y en cuanto tiempo se haya arribado a él. Asimismo, analiza la política de incentivos que ha implementado la autoridad para promover un mejoramiento de los servicios licitados como también los mecanismos de control de calidad que contribuirían a superar el modelo vigente.
\end{abstract}

Palabras clave: mediación, familiar, calidad.

\section{Abstract}

This article discusses the current situation of family mediation services tendered constatand that it has installed an express model of dubious quality that fails to adequately capture the principles that govern the discipline and that favors the deal no matter how and how long it has arrived him. It also analyzes the incentive policy that has implemented the authority to promote improvement of the services tendered as well as the quality control mechanisms that would help surpass the current model.

Key words: mediation, family, quality.

Abogada y mediadora, Magíster en Derecho con mención en Derecho Privado de la Universidad de Chile, docente de Derecho Civil y Mediación en la Facultad de Derecho de la Universidad de Talca. Directora del Colegio de Mediadores de Chile, A.G. Correo: apalavecino@yahoo.es 


\section{Antecedentes}

A partir de la entrada en vigor de la Nueva la Ley de Matrimonio Civil, el 17 de noviembre de $2004^{2}$, la mediación familiar adquiere existencia legal en nuestro país ${ }^{3}$-adscrita a un proceso judicial- asumiendo el Ministerio de Justicia la tarea de configurar y supervisar el registro de mediadores familiares como también la de llamar a licitación para proveer gratuitamente los servicios de estos profesionales hacia la comunidad, especialmente en el caso de la mediación previa y obligatoria vigente desde $2008^{4}$.

Desde su consagración legal, hace ya siete años, la autoridad ha ido midiendo la percepción de la comunidad respecto a los servicios de mediación familiar licitados, encargando estudios y auditorías a diversas entidades. Así por ejemplo, la Universidad de Concepción consultó por el grado de satisfacción a 531 usuarios de centros adjudicados durante los meses de febrero a julio del año 2006, en el contexto de la

2 Justamente, el párrafo tercero del capítulo VII de la Ley № 19.947 se denominaba De la mediación y la contemplaba para las causas de divorcio y separación, no para nulidad. El sentido de esta instancia era que los cónyuges regularan sus relaciones mutuas principalmente en lo relativo a los alimentos y al régimen de bienes, como también los alimentos, cuidado personal y relación directa y regular respecto de los hijos comunes. Por este motivo se abrió el registro de mediadores familiares a cargo del Ministerio de Justicia, dictándose un reglamento al efecto. Con la entrada en vigencia de la Ley de Tribunales de Familia un año después, el 1 de octubre de 2005, la mediación se extiende a otras causas de familia, instalándose el 15 de septiembre de 2008 como instancia obligatoria previa al juicio, para causas de alimentos, cuidado personal y relación directa y regular, merced a la reforma introducida por la Ley 20.286 .

3 Digo que adquiere existencia legal, porque la mediación existió naturalmente casi una década antes, desde 1996, ligada a proyectos pilotos de las corporaciones de asistencia judicial de Valparaíso, Santiago y Concepción. Una sistematización de la experiencia en la Corporación de la Región Metropolitana puede verse en: Alliende Luco, Leonor, Burgos Pizarro, Jorge, Correa Camus, Paula y Pérez Castillo, Sandra, El proceso de mediación, Editorial Jurídica de Chile, Chile, 2002.

4 El artículo 114 de la Ley de Tribunales de Familia dispone que los servicios de mediación respecto de las materias de mediación previa obligatoria “...serán gratuitos para las partes. Excepcionalmente, podrá cobrarse por el servicio, total o parcialmente, cuando se preste a usuarios que dispongan de recursos para financiarlo privadamente (...) Para las restantes materias, los servicios de mediación serán de costo de las partes y tendrán como valores máximos los que contemple el arancel que anualmente se determinará mediante decreto del Ministerio de Justicia. Con todo, quienes cuenten con privilegio de pobreza o sean patrocinados por las corporaciones de asistencia judicial o alguna de las entidades públicas o privadas destinadas a prestar asistencia jurídica gratuita, tendrán derecho a recibir el servicio gratuitamente. Para proveer los servicios de mediación sin costo para las partes, el Ministerio de Justicia velará por la existencia de una adecuada oferta de mediadores en las diversas jurisdicciones de los tribunales con competencia en asuntos de familia, contratando al efecto los servicios de personas jurídicas o naturales, a fin de que sean ejecutados por quienes se encuentren inscritos en el Registro de Mediadores. Las contrataciones a que se refiere el inciso precedente, se harán a nivel regional, de conformidad a lo dispuesto en la ley $N^{\circ}$ 19.886, de Bases sobre Contratos Administrativos de Suministro y Prestación de Servicios, y su reglamento. En todo caso, de contratarse mediadores mediante trato directo, los términos del mismo deberán ajustarse a iguales condiciones que las establecidas para la contratación de mediadores licitados, en lo que sea pertinente". 
primera licitación pública de estos servicios 5 . Por su parte, en el año 2008, la consultora Ernst \& Young efectuó un estudio exploratorio de 141 causas mediadas antes de la reforma introducida por la Ley $20.286^{6}$. Otro estudio realizado por TNS Chile en conjunto con la Subsecretaría de Justicia, a través de encuestas presenciales de satisfacción de usuarios, abarcó 1303 casos de mediación ingresados al sistema licitado en junio de 2009 y que Ilegaron a acuerdo total a marzo del año 2010 ${ }^{7}$. Recientemente, en enero de 2011, el Centro de Estudios y Asistencia Legislativa de la Universidad Católica de Valparaíso se adjudicó la auditoría externa para la evaluación de la calidad de los procesos de mediación, cuyos resultados fueron entregados al ministerio pero hasta el término de este artículo no se publicaban.

Un común denominador en los estudios y auditorías realizados hasta ahora es la constatación de que el proceso de mediación cuenta con legitimidad entre los usuarios, existiendo, en general, una favorable percepción respecto de los beneficios de participar en el mismo como vía para obtener acuerdos satisfactorios para las partes, en lugar de recurrir a la judicatura.

Pero ¿es suficiente que la comunidad valore y reconozca la mediación familiar como una opción válida para resolver sus conflictos? ¿O se debe avanzar en promover que esta instancia se profesionalice fortaleciendo los controles de calidad del servicio licitado?

No cabe duda que la preocupación de la autoridad por la calidad de la mediación familiar ha existido desde el inicio, sin embargo, se echa en falta que el Ministerio de Justicia, en función de los resultados y conclusiones de los estudios y auditorías efectuados al sistema licitado, implemente los ajustes necesarios en cuanto al diseño, instalación y sustentabilidad de esta política pública, con el propósito de garantizar su fortalecimiento y excelencia, pues con ello se contribuirá a optimizar el acceso a la justicia de la comunidad.

Ad portas de la próxima licitación de los servicios de mediación familiar, la ocasión es propicia para reflexionar sobre los aciertos y desaciertos del sistema vigente y proponer su mejora. Precisamente, este es el propósito del presente artículo.

5 Véase en World Wide Web: http://www.mediacionchile.cl/MinJusPubl/Upload/SPDocs/EST_6.pdf, [consultada el 14-09-2011]

6 Véase en World Wide Web:http://www.mediacionchile.cl/MinJusPubl/Upload/SPDocs/EST_10.pdf, [consultada el 14-09-2011].

7 Véase en World Wide Web:http://www.mediacionchile.cl/MinJusPubl/Upload/SPDocs/EST_13.pdf, [consultada el 14-09-2011]. 


\section{Diagnóstico ${ }^{8}$}

Cualquiera que se adentre en el actual sistema licitado de servicios de mediación familiar -cuyas bases administrativas fueron aprobadas por el Decreto Supremo № 904 de 2008 del Ministerio de Justicia- sin mucho esfuerzo comprobará empíricamente que la pregunta sobre la calidad del servicio es válida y que no coincide necesariamente con cuestionar la calidad de los profesionales mediadores. Primeramente, porque la mediación express reina en gloria y majestad, solo en muy contadas ocasiones las partes son citadas a una segunda sesión, agotándose todas las etapas del proceso en una sola reunión cuya duración fluctúa entre 45 a 90 minutos. Y es que el propio sistema licitado ha creado incentivos para esta rapidez. Ciertamente, conforme a las bases que regularon el actual proceso licitatorio, se remunera solo las causas terminadas con acuerdo total, aprobado judicialmente, sin importar el número de sesiones, y en un porcentaje inferior de ese valor, las causas frustradas a las que acudieron ambas partes al menos a una sesión. Y como lo que se paga en ambos casos son sumas bastante exiguas, la sustentabilidad económica de los centros licitados es posible en la medida que logren absorber un alto volumen de $\operatorname{causas}^{9}{ }^{10}$.

Se podrá replicar que la mediación como vía de resolución de conflictos se caracteriza por ser más expedita y desformalizada que el juicio, pero no se debe exagerar, porque en una sesión es imposible que se plasmen debidamente los principios que constituyen la base ideológica de esta disciplina ${ }^{11}{ }^{12}$. En efecto, la mediación es

8 Las apreciaciones que expongo en esta parte provienen de una constatación personal, luego de haber supervisado 4 centros licitados de mediación familiar en 2 regiones del país y haber presenciado 34 sesiones de mediación entre los meses de mayo y junio de 2011.

9 Así lo establece el capítulo segundo sobre bases técnicas del proceso licitatorio, punto 6, aprobado por el DS N 904 de 2008 del Ministerio de Justicia. Véase en World Wide Web: http://www.mediacionchile.cl/MinJusPubl/Upload/SPDocs/DEC904.pdf, [consultada el 26-09-2011].

10 En efecto, en las bases de licitación pública no se contemplaron mínimos de precios, entregando al mercado de oferentes la determinación de los mismos, sobre la base de la cuantificación de sus costos y de su margen de utilidad o remuneración. Esta modalidad determinó en muchos casos precios irrisorios, inferiores incluso que los valores fijados en la primera licitación del año 2006, poniendo en riesgo con ello la sustentabilidad económica de los centros licitados. Asimismo, propició injustificadas y, por ende, discriminatorias diferencias contractuales ante condiciones fácticas semejantes.

11 Marinés Suares explica que la mediación tiene su propia ideología, vale decir, su propio sistema de ideas, creencias y valores sobre el hombre y la sociedad. Así plantea que: "La mediación considera que los seres humanos son capaces de resolver por sí mismos sus conflictos y/o disputas en forma efectiva. Esto ocurre permanentemente, solo que algunas veces se empantanan; en mediación se busca rescatar esta capacidad que se encuentra, por algún motivo obstaculizada". De otra parte, indica que: "la esencia de la mediación pasa por la voluntariedad, es decir, por la decisión libre de realizar una negociación asistida". Aclara al respecto que aun cuando se establezca como instancia obligatoria previa al juicio, en tal caso a las partes solo se les exige acudir a un primer encuentro de mediación, pero no concluir todo el proceso porque "nadie puede ser obligado a negociar". Asimismo, la autora plantea que otro principio muy importante de la mediación es el protagonismo y coprotagonismo de las partes, el que se vincula con la responsabilidad que deben asumir respecto a sus acciones y las consecuencias 
propiamente un proceso, es decir, una secuencia o serie de actos que se despliegan en el tiempo, lo que usualmente requerirá un número variable de sesiones continuas, período durante el cual se procura generar una nueva pauta de interacción comunicacional entre las partes y un clima de confianza que propicie el entendimiento mutuo, cuya gestación no es súbita, ni menos mecánica, sino las más de las veces, gradual y paulatina, lo que redundará en la eficacia y estabilidad del acuerdo.

Igualmente, cabe cuestionar si el acuerdo es el único aspecto o el más relevante para evaluar el éxito de la mediación o si existen otros criterios cualitativos que también son importantes, como por ejemplo, el grado de participación de los usuarios, su percepción sobre el acceso a la justicia a partir de la experiencia de mediación, la perdurabilidad del acuerdo, entre otros ${ }^{13}$.

Enseguida, y como consecuencia de esta celeridad, casi nunca se escucha a los niños, no está incorporado como una práctica habitual en la metodología de los

de las mismas, es decir, en la mediación se debe propiciar que se hagan cargo de su situación y de la búsqueda de una solución a su conflicto, para lo cual el mediador debe legitimarlos y empoderarlos. Enseguida, la autora se refiere a la neutralidad, que se traduce en que el mediador no debe tomar partido por ninguna de las partes (imparcialidad), debe otorgarles las mismas posibilidades de participar en el proceso (equidistancia), debe ser equitativo y mantenerse neutral, colaborando en la deconstrucción de la disputa para que las partes la aborden desde nuevas perspectivas. Por último, se refiere a la confidencialidad tanto en las reuniones conjuntas como en las privadas. Suares, Marinés, Mediando en sistemas familiares, Editorial Paidós, Argentina, 2002, pp.28-40.

12 La ley 19.968 sobre tribunales de familia en el artículo 105 contempla seis principios que rigen la mediación familiar, a saber: igualdad, voluntariedad, confidencialidad, imparcialidad, interés superior del niño y opinión de terceros. Es evidente que estos principios no pueden desplegarse adecuadamente en una sola sesión de mediación. No debe olvidarse que el plazo máximo contemplado en el 110 de la ley es de 60 días contados desde que se le comunica al mediador su designación, prorrogables de común acuerdo por otros 60 . Entonces, no hay motivos valóricos, tampoco legales, que justifiquen la mediación express, claramente es una externalidad negativa del modelo licitatorio. Véase en World Wide Web: http://www.leychile.cl/Navegar?idNorma=229557, [consultada el 24-09-2011].

13 El enfoque transformador precisamente plantea que el acuerdo no ha de ser la meta primordial de la mediación, en cambio propone que: "La promesa original de la mediación reside en su capacidad para transformar el carácter de los antagonistas individuales y de la sociedad en general. A causa de su informalismo y consensualidad, la mediación puede permitir que las partes definan problemas y metas, en sus propios términos, convalidando de ese modo la importancia de dichos problemas y metas en la vida de las partes. Además la mediación puede apoyar el ejercicio de la autodeterminación en las partes, al decidir cómo resolver una disputa, o incluso si se lo hará; y puede ayudar a las partes a movilizar sus propios recursos (...) aumentar su propia capacidad para afrontar toda clase de circunstancias adversas, no solo las que rodean el caso presente, sino también las que podrán existir en situaciones futuras. Los participantes de la mediación han adquirido un sentido más claro de autorrespeto, de afirmación de sus propias fuerzas y de confianza en ellos mismos. Es lo que se ha denominado la dimensión revalorizante de la mediación". Asimismo, explica que: "la meta más importante consiste en originar el crecimiento moral y transformar el carácter humano (...) no es que la satisfacción y la equidad carecen de importancia, sino que la transformación de la conciencia moral y la conducta humana es incluso más importante". Baruch Bush, Robert y Folger, Joseph, La promesa de la mediación, Editorial Granica, S.A, Argentina, 2006, pp. 46 y ss. 
mediadores. Tampoco es propiciado por la autoridad de ningún modo. Quizá esto se deba en gran medida a la última reforma que experimentó la Ley de Tribunales de Familia que limitó la escucha de los niños en mediación a los casos en que sea estrictamente indispensable ${ }^{14}$. Pero lo cierto es que, cuando la edad, madurez y voluntad de los niños y adolescentes permite su participación, para conocer sus intereses y expectativas, debería ser oído, tanto más si se considera que es un sujeto de derecho y no un mero objeto de negociación entre los padres. Esta y no otra es la filosofía que emana del artículo 12 de la Convención de los Derechos del Niño' ${ }^{15}$.

Asimismo, una visita a los centros de mediación licitados permite advertir una alarmante precarización del empleo del profesional mediador pues, por regla general, los mediadores trabajan en condiciones modestas, con mobiliario básico, en lugares lóbregos, con deficientes condiciones de calefacción y ventilación y la mayoría está subcontratada. Evidentemente, los mediadores no lucran, ganan modestamente y toda economía en la implementación de los centros se traduce en mayores ingresos ${ }^{16}$. En otras palabras, nadie vive holgadamente dedicándose solo a esta actividad. Entonces,

14 La Ley 20.286 introdujo en la Ley de tribunales de familia el art. 105, referido a los principios de la mediación, que en la letra e) dispone: "Interés superior del niño: por el cual, en el curso de la mediación, el mediador velará siempre para que se tome en consideración el interés superior del niño, niña o adolescente, en su caso, pudiendo citarlos solo si su presencia es estrictamente indispensable para el desarrollo de la mediación".

15 El artículo 12 de la Convención de los Derechos del Niño dispone: "1. Los Estados Partes garantizarán al niño que esté en condiciones de formarse un juicio propio el derecho de expresar su opinión libremente en todos los asuntos que afectan al niño, teniéndose debidamente en cuenta las opiniones del niño, en función de la edad y madurez del niño. Con tal fin, se dará en particular al niño oportunidad de ser escuchado, en todo procedimiento judicial o administrativo que afecte al niño, ya sea directamente o por medio de un representante o de un órgano apropiado, en consonancia con las normas de procedimiento de la ley nacional". Véase en World Wide Web: http://www2.ohchr.org/spanish/law/crc. htm, [consultada el 24-09-2011].

16 Al respecto, el Colegio de Mediadores de Chile A.G., representado por su presidente, Juan Pablo Cárdenas Castro, hizo saber su malestar al Ministro de Justicia, mediante carta de fecha 28 de septiembre de 2011, en la cual plantea: "Considerando que el mediador o mediadora -recurso humano, dicho figuradamente- es el componente fundamental en todo proceso de mediación, nos hemos formado la opinión fundada que prácticamente todas las disfuncionalidades e irregularidades (...) dejan en evidencia un sistema que ha recargado injustamente sobre ellos, generalmente personas que son profesionales de esfuerzo, en su mayoría trabajadores sociales, psicólogos, abogados y, en menor medida otros profesionales de las ciencias sociales, la pedagogía y las comunicaciones. Se debe tener presente que no es justo que existiendo un importante presupuesto estatal para financiar los servicios de mediación previstos por la ley, los mediadores reciban ingresos irrisorios e indignantes, absolutamente reñidos con la responsabilidad jurídica y profesional inherente a su misión, e insuficientes para una básica sustentación dentro de la actividad, generando un sentimiento de desprotección, inseguridad e injusticia. En esta línea, las principales anomalías en perjuicio de los mediadores se pueden resumir de la siguiente manera:

a) Mediadores/as contratados a honorarios, no obstante cumplir jornadas o medias jornadas y posición de subordinación laboral respecto de las empresas adjudicatarias durante todo el período en que dura el contrato entre el Ministerio de Justicia y dicha empresa.

b) Muchas veces se obliga a los mediadores/as no solo a cumplir horarios, sino a realizar labores administrativas, lo que no es coherente con el sistema de remuneración a base de honorarios. 
el mediador muy calificado no tiene gran acicate para convertirse en licitado, si la docencia o el ejercicio liberal de su profesión, en su caso, le reportan mayor ganancia. A lo sumo constituirá una actividad complementaria. Aunque en el caso de profesionales cuyo campo laboral es limitado o existe demasiada competencia, la mediación constituye la única oportunidad de trabajo, motivo por el cual muchos de ellos aceptan estas condiciones laborales deficientes sin chistar ${ }^{17}$. Sería muy importante que en próximas licitaciones y con el propósito de contrarrestar estos males, el Estado exija a las personas jurídicas adjudicatarias el cumplimiento de la normativa laboral respecto del personal que trabaje para ellas, efectuando el adecuado control de manera de evitar el ocultamiento de la relación laboral y la consiguiente vulneración de los derechos de los trabajadores, en especial, los mediadores.

c) La gran mayoría de los mediadores se ven impedidos de ejercer derechos laborales como salario justo, vacaciones o estabilidad relativa en el empleo, ni contar con cotizaciones previsionales y de salud. Sin perjuicio de ello, en la práctica estos mismos mediadores están obligados a cumplir horario, realizar labores administrativas, incluso contribuir a gastos generales del centro respectivo.

d) En relación al pago por mediaciones realizadas, las empresas actúan con absoluta discrecionalidad. De este modo, cuando hay procesos con acuerdo se paga a los mediadores actuantes una cifra que varía entre el $15 \%$ y el $40 \%$ del valor total de la mediación ofertada por el centro. Y cuando el proceso de mediación finaliza sin acuerdo, si bien con la asistencia de ambas partes, también el pago varía entre el $15 \%$ y el $40 \%$ del valor total de la mediación ofertada por el centro.

e) En algunos centros las mediaciones frustradas en que se realizó al menos una sesión con ambas partes (causa en trámite) simplemente no son pagadas, privándose al mediador de la asignación mínima establecida en las Bases de licitación, y forzándolo a contribuir a los gastos operativos del respectivo centro.

f) Hay regiones del país, como la Cuarta (Coquimbo), y la isla de Chiloé, donde se dan prácticas monopólicas que impiden el acceso al sistema licitado y, aun, al mismo registro público de la SEREMI, donde los centros no admiten alumnos en práctica con el fin de evitar futura competencia.

g) También se han detectado malas prácticas que coartan la libertad de los mediadores/as, como por ejemplo, que los agentes que participan en licitaciones condicionen la posibilidad de trabajar en los centros licitados a un compromiso previo de exclusividad, totalmente reñido con la libertad de trabajo y la dignidad humana.

La subcontratación de mediadores, muchas veces bajo insuficientes cuando no precarias condiciones de trabajo y remuneraciones contrasta con los recursos obtenidos de manera desmesurada por las empresas adjudicatarias, cuyos dueños o gestores no tiene un compromiso especial con los servicios ni con los mediadores profesionales que los brindan directamente, con grave desmedro de estos. Cabe agregar que, en este escenario, más allá de las adjudicaciones y contratos públicos, salta a la vista que la profesión de mediador rara vez permite hacer de ella un modo de vida sustentable para quienes la han estudiado y desean practicarla con seriedad y dignidad".

17 El modelo de licitación escogido por el Estado en 2008 hizo competir a los mediadores por precio estimulando la despreocupación por los usuarios y la práctica desprolija de los mediadores. Asimismo, las condiciones de la licitación propiciaron la conformación de empresas, normalmente sociedades de profesionales u otras formas de PYMES, también a la postulación de personas individuales y, con mucha menor frecuencia, universidades o instituciones sin fines de lucro. Lamentablemente, en la mayoría de los casos el principal capital de los gestores no ha sido el saber o la experticia mediadora, sino la organización y la economía de escalas, y su principal interés, su rentabilidad en el corto plazo, sin mayores miramientos al tipo de servicios que deben brindar. 
Ahora bien, a pesar de la mediación express, no se puede afirmar que los mediadores licitados incurran abierta y deliberadamente en infracciones groseras a los principios más básicos que inspiran esta disciplina, como por ejemplo, imponer un acuerdo, vulnerar la confidencialidad, o favorecer a alguna de las partes en desmedro de la otra, antes bien, la mayoría de ellos realiza su labor con gran esmero y vocación. En los discursos de apertura explican de manera didáctica en qué consiste la mediación y sus características, preocupándose de verificar si hay procesos o sanciones por violencia intrafamiliar entre las partes, lo que la autoridad ha cautelado con bastante énfasis. Pero un análisis un poco más fino permite advertir deficiencias, especialmente ante escaladas del conflicto $^{18}$, pues la regla general es que ante este escenario no se haga mayor despliegue de técnicas y, por el contrario, se certifique raudamente el carácter de mediación frustrada debido a los incentivos perversos que ha generado el actual sistema licitado, según se indicó. De manera que, los mediadores licitados tienden a deshacerse pronto de aquellos usuarios que no muestran demasiada capacidad negociadora, por el costo de oportunidad que trae aparejada la prolongación del proceso.

También puede apreciarse en grado considerable un estilo paternalista de ejercer la mediación a través de la "consejería", esto es, que el mediador manifieste en algún momento de la sesión, motu proprio o a petición de alguna las partes, lo que a su juicio deben hacer, o lo que en su opinión es un buen padre o una buena madre, o lo que sienten los hijos -sin siquiera escucharlos, como ya se dijo- lo que ciertamente socava el protagonismo de los participantes y la neutralidad del mediador. Es conveniente recordar que el mediador no interviene en el proceso como experto en la materia del conflicto, es decir, como psicólogo, abogado u orientador familiar. La habilidad del mediador consiste en facilitar la comunicación entre las partes, restablecer o potenciar su capacidad negociadora, lo que no se logra precisamente aconsejándolos ${ }^{19}$. No obstante lo dicho, la generalidad de los usuarios queda conforme por lo expedito del trámite en comparación con un juicio que es el referente.

18 Suares explica la fase de estallido del conflicto como aquella en que "cada una de las partes se fija más en su posición y se autocentra en sí misma, haciéndose sorda a lo que dice o hace la otra. Las pautas de interacción entre los integrantes se rigidizan. Se establece una relación de franca competencia que comienza a teñir todas las interacciones". Ante este escenario, según la autora argentina, la función del mediador es doble: preventiva, es decir, debe frenar la escalada evitando que devenga en una etapa destructiva; y otra asistencial, la que tiene como propósito disminuir la tensión del conflicto, desescalarlo, promocionando pautas colaborativas de relación entre las partes. Suares, Marinés, obr. cit., pp. 54 y 55. Las intervenciones para desescalar un conflicto pueden ser variadas, pero el rol del mediador ha de ser protagónico: lo primero es recordar que una regla de oro en mediación es que se prohíben las descalificaciones, también puede separar momentáneamente a las partes y efectuar sesiones privadas, es decir, hacer una mediación-puente hasta que las partes puedan volver a conversar. Otra técnica útil es la legitimación, promoviendo la comprensión del otro y de su situación.

19 Como explican Diez y Tapia: "El ejercicio del rol de mediador tiene mucho en común con el ejercicio de otras profesiones en las que también se trabaja con personas. Pero tiene una diferencia que es básica. Si uno es médico o abogado, el tipo de persona que sea el paciente o cliente es importante, pero uno trabajará -desde su ciencia- para curar la enfermedad o o resolver el caso de acuerdo con ciertos patrones objetivos. Específicamente su ciencia, y no tanto como sean las personas que acuden a él, 
Otro aspecto digno de comentar es que las mediaciones que versan sobre alimentos están sujetas a una serie de restricciones legales referidas a los montos mínimos y la fijación de alimentos provisorios que en ocasiones son imposibles de aplicar en la práctica y que constriñen tanto el actuar del mediador como la libertad de las partes para arribar a un acuerdo ${ }^{20}$. Lo propio ocurre con las mediaciones que tratan sobre la entrega del cuidado personal de los niños a un tercero. En ambos casos, los mediadores deben fundamentar muy minuciosamente, en las actas de mediación, las particularidades del caso concreto e incluso acompañar antecedentes probatorios que justifiquen las decisiones de las partes, pues de lo contrario los jueces de familia no las aprobarán por "ser contrarias a derecho", situación que distorsiona el genuino espíritu de la mediación especialmente en lo referido al protagonismo de las partes como en cierto grado también, a la confidencialidad ${ }^{21}$.

Por último, se puede señalar que es usual que algunas mediaciones nunca se lleven a cabo por inasistencia de una o de ambas partes. Esto es particularmente marcado en centros ubicados en lugares apartados, que si bien son asiento de tribunal, la ruralidad o lejanía de la zona explica esta deserción. Por ello, en mi opinión, no se justificó que en esta última licitación se haya exigido implementar oficinas en estos lugares porque en la práctica se agenda mediaciones una vez cada quince días y

le aportará los elementos necesarios para trabajar con la enfermedad o el problema de esas personas. Con esos elementos, el médico o el abogado le dirán al paciente o al cliente qué es 'lo que hay que hacer' para curar la enfermedad o encarar correctamente la cuestión legal. En mediación no funciona así. No puede suceder sencillamente porque no hay, ni habrá nunca, un tratado de conflictos posibles entre las personas que nos dé los elementos necesarios como para decirles a las personas 'lo que hay que hacer' a fin de resolver el conflicto (...) El mediador, en cambio, arranca trabajando frente al caso desde la ignorancia. Él no sabe nada del conflicto que tienen esas personas, ni las conoce, ni puede presuponer sus intereses y necesidades (...) Muy probablemente las partes esperarán respuestas del mediador a medida que expongan sus posiciones frente al conflicto, intentando poner al profesional en una posición de 'saber'(...) No hay dónde saber, como no sea de esas mismas personas con las que estamos trabajando. Las que saben son ellas. Y nuestra función es ayudarlos a encontrar sus propias respuestas". Diez, Francisco y Tapia, Gachi, Herramientas para trabajar en mediación, Editorial Paidós, Argentina, 1999, pp.171 y 172.

20 Muñoz plantea al respecto que: "En términos reales, el mediador que actúa en el sistema nacional o público de mediación familiar viene a ser una especie de representante de la ley, viéndose involuntariamente forzado a hacer una labor de convencimiento a los participantes para que el alimentante asuma el compromiso mínimo de pagar el $40 \%$ de un ingreso mínimo remuneracional por un hijo alimentario, pues la ley impide fijar un monto menor a ese. Este límite legal se vuelve un factor en contra de los principios que todo mediador debe observar porque indirectamente genera una imposición, no ejercida por el mediador sino que por voluntad de la ley que rige el fondo de esta materia". Muñoz Herrera, María Angélica, Mediación y pensión de alimentos, Véase en World Wide Web: http://www. colegiodemediadores.cl/muestra_nota.php?id=60, [consultada el 30-09-2011].

21 Afirmo que se incumple el deber de confidencialidad porque al menos el acta en que se acuerda entregar el cuidado personal de un niño a un tercero debe subinscribirse en su respectiva partida de nacimiento, según lo previsto en los artículos 225 y 227 del C.C., de manera que tienen acceso a su contenido pormenorizado los funcionarios del Registro Civil encargados de efectuar dicho trámite. 
aún así la gente no llega. Me consta que algunos mediadores han informado del nulo movimiento de estos centros a la autoridad, veremos si esto se traducirá en dejar sin efecto esta exigencia en una próxima licitación.

En resumidas cuentas, las condiciones de la última licitación han consolidado un modelo de mediación express de dudosa calidad que si bien deja satisfecha a la mayoría de los usuarios no logra plasmar debidamente los principios que rigen esta disciplina.

\section{Política de incentivos del Ministerio de Justicia: ¿es suficien- te para promover la calidad de la mediación familiar licita- da?}

El 15 de julio de 2011, mediante la resolución exenta № 1793 de la Subsecretaría de Justicia, se aprobó el instructivo para el pago de incentivos a los centros de mediación familiar contratados a lo largo del país, cuya finalidad declarada es motivar una mejora en la prestación del servicio de mediación, en el marco de la licitación vigente. Este acto administrativo estableció indicadores que, en el caso de ser cumplidos satisfactoriamente por los centros licitados, dan derecho a percibir un incentivo económico. Esos indicadores se vinculan con tres aspectos, a saber: la administración de las causas por parte de los centros de mediación adjudicados, el nivel de conocimiento de los mediadores y la satisfacción usuaria respecto del servicio recibido.

Respecto al primer indicador, se cumplirá en la medida que los mediadores licitados ingresen al menos el 90\% de las causas derivadas a más tardar el día siguiente hábil desde la comunicación al sistema informático de mediación familiar (SIMEF) y acompañen los documentos de respaldo de al menos el $75 \%$ de tales causas. Innegablemente es importante para la autoridad llevar un control riguroso de las causas sometidas a mediación, lo que a su vez le permita contar con datos estadísticos fidedignos de los centros licitados, sin embargo, no considero que se trate de un aspecto gravitante en la calidad del servicio que vaya a incidir de manera decisiva en la percepción sobre la mediación familiar, de cara al exterior. Tampoco estimula el refuerzo de aspectos cualitativos del ejercicio de esta actividad. Implícitamente incita a los mediadores adjudicados a privilegiar el cumplimiento de requisitos de gestión administrativa en lugar de preocuparse de potenciar la calidad de su tarea profesional.

El segundo indicador se mide en función de que los mediadores de los centros licitados obtengan un promedio de calificación en conocimientos específicos igual o superior a 5,5. Al respecto, Viveros se pregunta qué ha motivado a la administración estatal del sistema a examinar el nivel de conocimientos jurídicos de sus contrapartes adjudicadas cuando la formación era precisamente uno de los requisitos de mayor peso en la licitación, por lo que debería presumirse la competencia de los adjudica- 
tarios en cuanto a conocimientos ${ }^{22}$. Por mi parte estimo que obtener buena nota en una prueba de conocimientos teóricos básicos acerca de la mediación no garantiza forzosamente que la práctica de la disciplina se ajuste a los mismos, máxime cuando la mediación no se dilata más allá de una sesión. En efecto, estimo que la calidad del mediador se manifiesta más bien en su capacidad para manejar efectivamente el proceso, desplegar habilidades y técnicas y efectuar intervenciones oportunas en las situaciones que se le presentan, propiciando que las partes encuentren una salida razonablemente satisfactoria a su conflicto. Entonces, debería construirse un instrumento técnico que evalúe estos comportamientos y en función de los resultados aplique incentivos.

Por último, en cuanto al tercer indicador, se cumplirá cuando el promedio de calificación del centro licitado en la encuesta de satisfacción de usuarios y/o instituciones relacionadas al proceso de mediación sea igual o superior a 5,5. Desconozco si la encuesta mide solo aspectos de gestión administrativa del centro adjudicado o también el rol profesional de los mediadores.

Aunque es prematuro juzgar la eficacia de esta política de incentivos en orden a promover la calidad del sistema licitado debido a su reciente implementación, me atrevo a vaticinar que los indicadores que la conforman serán insuficientes para garantizar una mediación familiar licitada de excelencia, sencillamente porque no apuntan a subsanar las deficiencias observadas como consecuencia de haberse instalado un modelo de mediación express, al que solo le interesa el acuerdo, sin importar cómo y en cuanto tiempo se haya arribado a él, o la calidad y sustentabilidad del mismo.

22 El autor agrega que: "Aunque es riesgoso generalizar, pues consta el trabajo dedicado y de calidad que realizan muchos mediadores y mediadoras del sistema licitado, a poco andar ha ido confirmándose, por la vía de reclamos de los usuarios y el testimonio de los colegas, las deficiencias de prestadores licitados o subcontratados que exhiben bajo nivel de desempeño o prácticas de dudosa coherencia. Al parecer, a partir de esta preocupante percepción, cobró fuerza en el MINJU la idea de 'hacer volver a la escuela' a los mediadores licitados para examinar su competencia y saberes, como si la acreditación de diplomas, postítulos, magísteres y cursos diversos durante la licitación no hubiere bastado para presumir que los mediadores que el Estado contrataría estaban y están profesionalmente preparados. En este punto la fuerza de los hechos ha indicado otra cosa y, desde el punto de vista del diseño del siste$\mathrm{ma}$, se ha revelado una falla sensible y determinante. En efecto, parece que hay mediadores a quienes no solo les falta experiencia -factor que fue subvalorado en el proceso licitatorio, pero que con dedicación y tiempo puede superarse- sino que habría algunos que no entienden cabalmente la complejidad de su rol profesional...". Viveros Caviedes, Felipe, Mediadores licitados rinden examen: ¿Por qué y para qué?, en World Wide Web: http://www.colegiodemediadores.cl/muestra_nota.php?id=52, [consultada el 24-09-2011]. 


\section{¿De qué manera se podría asegurar la calidad de los servicios de mediación fami- liar licitada?}

De acuerdo al diccionario de la Real Academia Española, calidad es la "propiedad o conjunto de propiedades inherentes a algo, que permiten juzgar su valor". En un segundo sentido, señala que es "superioridad, excelencia" ${ }^{23}$. A partir de esta definición, se puede afirmar, entonces, que la mediación será de calidad en la medida que no se afecte su esencia ni tampoco las ventajas comparativas que ofrece y que la distinguen de otras vías de resolución de conflictos. Pero ¿qué mecanismos permiten asegurar la calidad de la mediación?24.

A propósito de la noción de control de calidad, Rosselot indica que: "En el ámbito de los servicios personales y más si son prestados y tienden a beneficiar específicamente a personas, la calidad puede ser entendida con el nombre de 'hacer bien las cosas'. Para el ejecutor o proveedor es una meta y para el usuario una condición que debe ser cubierta y que exige ser comprobada. Constituye, por lo tanto, un hecho de demostración del que lleva a cabo el servicio frente a quien lo utiliza y, desde el momento que representa una obligación de otorgar un beneficio entre personas, traduce un valor ético que requiere ser respaldado, como toda acción y efecto en un mundo prudente sino suspicaz, por la mejor evidencia posible ${ }^{\prime 25}$.

Por su parte, Moffit plantea que para resolver la cuestión de la calidad "todos los involucrados en mediación deberían indagar en otras actividades profesionales para reconocer los indicadores de los mecanismos más eficaces" ${ }^{\prime 26}$. Según el autor, existen cuatro métodos básicos para asegurar la calidad en cualquier práctica o profesión, a saber: mecanismos de punto de inicio para el sector público, mecanismos de punto

23 Diccionario de la Lengua Española, Real Academia Española, vigésima segunda edición, 2001, p. 401.

24 Álvarez y otras se preguntan: “¿A qué nos referimos cuando hablamos de calidad? Un primer acercamiento nos indica que la calidad abarca 'la totalidad de los aspectos y características de un producto, servicio o proceso relacionados con su capacidad de satisfacer necesidades explícitas o implícitas de todos los sectores interesados'. Y, además, la calidad se refiere 'al grado de perfección de un producto o servicio, al control de variabilidad de un producto o servicio, al control de variabilidad de un proceso y al nivel de satisfacción del cliente o usuario respecto del mismo' (Giandoménico, 2008)". Álvarez, Gladis, D’Alessio, Damián y Amilodare, Ana María, Calidad en mediación en Brandoni, Florencia (comp.), Hacia una mediación de calidad, Editorial Paidós, Argentina, 2011, pp. 237-238.

25 Rosselot J, Eduardo. Aseguramiento de la calidad profesional.: Un nuevo marco ético para el ejercicio de la medicina /en/ Revista Médica de Chile, [online], 1999, vol.127, n.11 [citado 2011-0929], pp. 1375-1383 . Disponible en World Wide Web: <http://www.scielo.cl/scielo.php?script=sci_ arttext\&pid=S0034-98871999001100013\&lng=es\&nrm=iso>. ISSN 0034-9887. doi: 10.4067/ S0034-98871999001100013, consultada el 27-09-2011.

26 Moffit, Michael, Las cuatro formas de asegurar la calidad del mediador (y por qué ninguna funciona) en Brandoni, Florencia (comp.), Hacia una mediación de calidad, Editorial Paidós, Argentina, 2011, p. 189 . 
de finalización para el sector público, mecanismos de punto de inicio para el sector privado y mecanismos de punto de finalización para el sector privado.

En cuanto a los primeros, se vinculan con la entidad gubernamental que desempeña un papel activo para asegurar la calidad del servicio, en nuestro caso, el Ministerio de Justicia, que concede la licencia de acceso o autorización para desempeñar la actividad. De manera que se impone una barrera inicial pero también se puede exigir requisitos para mantener la autorización, como por ejemplo, la capacitación permanente.

La mediación familiar en Chile se ha concebido como una actividad que exige título profesional de cualquier área y determinadas horas de especialización teórica y práctica en mediación. En efecto, el inciso final del art. 112 inciso $4^{\circ}$ de la Ley de Tribunales de Familia, dispone que para inscribirse en el registro de mediadores se requiere poseer título profesional de una carrera que tenga al menos ocho semestres de duración; acreditar formación especializada en mediación y en materias de familia o infancia y no haber sido condenado por delito que merezca pena aflictiva ni por actos constitutivos de violencia intrafamiliar. Además, se debe disponer de un lugar adecuado para desarrollar la mediación. El reglamento se encarga de especificar que la exigencia de formación en mediación es de 180 horas teóricas y 40 horas prácticas ${ }^{27}$.

Cabe preguntarse si esta barrera inicial impuesta por la ley y la autoridad es suficiente o las exigencias para integrar el registro de mediadores son más bien mínimas y se justificaron en su momento por el carácter embrionario de la disciplina, pero en la actualidad precisan una mayor estrictez.

Respecto a la exigencia de capacitación permanente, no se trata de un requisito que se deba cumplir para permanecer en el registro de mediadores, pero en el caso de los prestadores licitados, tanto en las actuales como en las nuevas bases administrativas y técnicas -recientemente aprobadas por Resolución № 189 de 29 de agosto de 2011, de las que ya tomó razón la Contraloría- se acentúan las exigencias de formación, experiencia y disponibilidad horaria del mediador, lo que lamentablemente no guarda proporción con los ingresos que les reportarán sus servicios de resultar adjudicados, ni con la escasez de oferta de cursos de postítulo y postgrado centrados únicamente en mediación ${ }^{28}$. Me parece loable que la autoridad se ocupe de elevar

27 El art. $4^{\circ}$ del DS 769 del Ministerio de Justicia de 25 de mayo de 2009, que contiene el Reglamento de la Ley de Tribunales de Familia, indica que toda persona interesada en integrar el registro de mediadores familiares deberá acreditar estudios de, a lo menos, 180 horas teóricas y 40 horas de práctica efectiva. Del total de horas teóricas, un mínimo de 80 deberán estar centradas en el proceso de mediación.

28 Así, puede verse en las nuevas bases de licitación: "2 Factor: Formación profesional en mediación de los mediadores que se postulan (...) Para la acreditación de este factor solo se considerarán los antecedentes académicos de formación especializada en mediación. Los criterios de evaluación serán los si- 
los estándares de formación del mediador licitado, pero debe hacerlo en términos razonables y posibles, teniendo en cuenta la oferta académica existente, como también la justa retribución ante tales exigencias, porque reitero, si los servicios licitados son mal remunerados, no habrá acicate para que el profesional altamente calificado participe de la licitación, salvo que lo anime algún propósito filantrópico o académico, porque no es menos cierto que las opciones para ejercer la mediación familiar escasean de no estar inmerso en el sistema licitado.

Los mecanismos de punto de finalización para el sector público, de acuerdo al autor, dicen relación con las medidas para sancionar a los profesionales cuyo desempeño es inferior al nivel mínimo exigido. Sobre este punto se puede señalar que, el artículo 113 de la ley de tribunales de familia, prevé la aplicación de sanciones a los mediadores familiares por incumplimiento de sus obligaciones, que van desde amonestaciones y suspensiones hasta la cancelación de la inscripción, mediante procedimiento seguido ante la Corte de Apelaciones correspondiente al territorio jurisdiccional donde ejercen su actividad ${ }^{29}$. Por su parte, el Ministerio de Justicia lleva

guientes: a) Solo se considerarán para la atribución de puntaje los diplomados, postítulos, magísteres y doctorados en mediación, terminados y aprobados a la fecha de presentación de las ofertas. No se considerarán los talleres, seminarios, cursos, etc. (...) $3^{\text {er }}$ Factor: Formación profesional en otras materias de los mediadores que se postulan: a) Solo se considerarán para la atribución de puntaje los diplomados, postítulos, magísteres y doctorados en materias vinculadas a la infancia, adolescencia, familia, género, violencia intrafamiliar y derecho de familia, terminados y aprobados a la fecha de presentación de las ofertas. No se considerarán los talleres, seminarios, cursos, etc. (...) $4^{\circ}$ Factor: "Docencia en mediación familiar de los mediadores que se postulan: a) Solo se considerará la docencia en mediación en cátedras en instituciones de educación superior. No serán considerados en este factor, las ponencias, seminarios, dictación de talleres o cursos que no formen parte de un programa de estudio de alguna carrera o grado académico, diplomado o postítulo impartido por una institución de educación superior. $5^{\circ}$ Factor: Resultado del examen rendido por los mediadores que se postulan. El Ministerio de Justicia, en el marco de cada proceso licitatorio (...) tomará exámenes a todos los mediadores que formen parte del Registro de Mediadores y que deseen ser parte integrante de una nómina para la prestación de los servicios de mediación familiar en un determinado proceso licitatorio". Véase en World Wide Web:https:// www.mediacionchile.cl/MinJusPubl/Sitio/documentos/pdf/Bases_Mediacion_Res_188_29_de_agosto_de_2011.pdf, pp. 17 y ss., [consultada el 25-09-2011. Se advierte una discordancia total entre las exigencias de formación, experiencia y disponibilidad horaria del mediador, por un lado, y, la irrisoria remuneración de sus servicios, por otro. Verdaderamente un absurdo. Me pregunto cuánto ofrece el Ministerio de Justicia cuando licita las defensorías laborales o penales. Nuevamente el pariente pobre de las reformas procedimentales de justicia sigue siendo familia.

29 Los incisos $2^{\circ}$ y siguientes de este precepto señalan textualmente: "En caso de incumplimiento de sus obligaciones o abuso en el desempeño de sus funciones, el mediador inscrito podrá ser amonestado o suspendido en el ejercicio de la actividad por un período no superior a los seis meses. Asimismo, en casos graves, podrá decretarse la cancelación de la inscripción. Impuesta esta última, no podrá volver a solicitarse la inscripción.

"Las sanciones serán ordenadas por cualquiera de las Cortes de Apelaciones dentro de cuyo territorio ejerciere funciones el mediador, a petición del interesado que reclamare contra los servicios prestados, de la institución o persona jurídica a que pertenezca el mediador, de cualquier juez con competencia en materias de familia del territorio jurisdiccional de la Corte, o de la respectiva Secretaría Regional Ministerial de Justicia. 
un registro público de todas las sanciones aplicadas a los prestadores de servicios de mediación, personas naturales o jurídicas, por la infracción o incumplimiento de las obligaciones establecidas en las bases para la contratación de servicios de mediación familiar ${ }^{30}$.

Siguiendo a Moffit, constituye una fortaleza que en nuestro caso el Estado pueda privar de la autorización para ejercer al mediador desidioso, pero la deficiencia que persiste es la ausencia de una delimitación clara y precisa respecto a lo que se ha de entender como una buena práctica de mediación familiar ${ }^{31}$.

En cuanto a los mecanismos de punto de inicio para el sector privado, se refiere al prestigio que tiene el prestador en el mercado y las razones por las cuales uno lo elegiría para atender su caso. Se caracterizan por ser "fuentes de influencia no gubernamental que definen quién obtiene el trabajo y la forma en que los profesionales lo realizan" 32 , como por ejemplo, las asociaciones de profesionales, las firmas de mediadores y los códigos de ética profesional.

Al respecto, es interesante señalar que el Colegio de Mediadores de Chile A.G. se constituyó en el año 2002 como una asociación de profesionales destinada a promover la racionalización, desarrollo, difusión, perfeccionamiento y protección de la actividad profesional de la mediación, y de las conexas a dichas actividades comunes ${ }^{33}$.

En diciembre de 2010 este organismo sometió a aprobación de la asamblea general de asociados un proyecto de código de ética de la profesión mediadora ${ }^{34}$ que

"La Corte resolverá con audiencia de los interesados y la agregación de los medios de prueba que estimare conducentes para formar su convicción.

"Las medidas que en ejercicio de estas facultades adoptaren las Cortes de Apelaciones, serán apelables, sin perjuicio del derecho del mediador para pedir reposición. La tramitación del recurso se sujetará a lo dispuesto en los incisos segundo y tercero del artículo 551 del Código Orgánico de Tribunales.

"La resolución será comunicada a la correspondiente Secretaría Regional Ministerial de Justicia para su cumplimiento, el que se hará extensivo a todo el territorio de la República. Impuesta la cancelación, el mediador quedará inhabilitado para actuar, debiendo proveerse una nueva designación respecto de los asuntos que tuviere pendientes. Por su parte, impuesta una suspensión, el mediador deberá continuar, hasta su término, con aquellos asuntos que se le hubieren encomendado en forma previa".

30 Véase en World Wide Web: http://www.mediacionchile.cl/MinJusPubl/Upload/SPDocs/Sanciones/Sanciones_al_05_09_2011.pdf, [consultado el 25-09-2011].

31 Moffit, Michael, obr. cit., p. 201.

32 Moffit, Michael, obr. cit., p. 195.

33 Sus funciones son, entre otras, representar los intereses de sus asociados y, en general, los de la comunidad profesional de los mediadores, ante todo tipo de autoridades y organismos públicos y privados; difundir, promover y perfeccionar la práctica de la mediación; facilitar el intercambio académico, gremial y social entre personas y organizaciones que trabajan, estudian o se interesan profesionalmente en la resolución cooperativa de conflictos a nivel nacional e internacional.

34 Véase en World Wide Web: http://www.colegiodemediadores.cl/muestra_nota.php?id=59, [consultada el 30-09-2011] 
en su título $\mathrm{V}$ contempla la conformación de un tribunal de ética entre cuyas funciones destaca la de conocer y resolver los conflictos y situaciones particulares que fueren sometidos a su conocimiento por parte de cualquier socio o miembro del colegio o por cualquier persona que estimare haber sido afectada por la actuación profesional de alguno de sus socios o miembros colegiados. Por tratarse de una normativa de tan reciente data, a la fecha no se ha incoado proceso disciplinario alguno.

En este sentido, estimo que un mediador colegiado que está dispuesto a someterse a un código y tribunal de ética que regulen su desempeño profesional debería gozar de mayor credibilidad y prestigio que aquel que no esté afiliado y esto tendría que ser valorado por el Estado, asignando el puntaje respectivo en las próximas licitaciones.

Por último, respecto a los mecanismos de punto de finalización del sector privado, están referidos a los "cursos de acción adoptados por los usuarios insatisfechos en contra de los profesionales que presuntamente incurrieron en un comportamiento impropio" ${ }^{\prime 35}$. Básicamente, se trata de las demandas de particulares en contra de mediadores por mala praxis. Este mecanismo de control de calidad funcionará, según Moffit, en la medida que pueda tener publicidad.

Sobre este tópico, es indudable que la obligación del mediador es de medios y no de resultado, puesto que el mediador no está obligado a producir la solución al conflicto sometido a mediación, sino más bien a poner todos los recursos a su alcance, de manera diligente y concienzuda, para ayudar a las partes a buscar por sí mismas una solución al conflicto y sus efectos ${ }^{36}$. Esta conclusión se ve reforzada por la propia ley cuando señala que el mediador es un tercero "sin poder decisorio" ${ }^{37}$. Por ello, es inaceptable que las bases de licitación circunscriban casi exclusivamente el pago de los servicios licitados a mediaciones con acuerdo, como si se tratara de una obligación de resultado del mediador.

De otra parte, encontramos aquí otro argumento que refuerza nuestra crítica al modelo express de la mediación licitada, pues resulta improbable pensar que un mediador ha hecho todo lo que está a su alcance, el máximo despliegue de su pericia y

35 Moffit, Michael, obr. cit., p. 196.

36 Como explica Barcia: "La obligación de medio es aquella en que el deudor pone a disposición del acreedor sus conocimientos en determinada ciencia o arte, sin obligarse a un resultado concreto. Ello se da en el trabajo de las profesiones liberales, como las que dependen de abogados, médicos u otros". Añade que: "La importancia de esta clasificación consiste en que la carga de la prueba se altera en las obligaciones de medio. En ellas será el acreedor el que debe probar que el deudor incumplió, no poniendo a disposición del acreedor sus conocimientos o lo hizo de forma insuficiente o negligente". Barcia Lehmann, Rodrigo, Lecciones de Derecho Civil. De la teoría de las obligaciones. Tomo III, Editorial Jurídica de Chile, Chile, 2010, p.19.

37 Art. 103 de la Ley 19.968. 
técnica para ayudar a las partes a resolver un conflicto, cuando la mediación ha durado solo una sesión, descontando que sean ellas las que decidan no perseverar en esa instancia. Al menos, será dificultoso para el mediador probar que actuó diligentemente.

Ahora bien, no solo se librará de responsabilidad cuando las partes hayan arribado a acuerdo, pues como aclara Moffit: "La obligación puede surgir específicamente del convenio de mediación pobremente redactado por el mediador..." ${ }^{38} y$, en general, de toda conducta que sea la causa directa de un daño para una de las partes o para un tercero ${ }^{39}$.

Considero que el entramado de mecanismos revisado panorámicamente, en versiones puras e híbridas, podría contribuir a materializar un efectivo control de calidad de la mediación familiar licitada. Por de pronto, urge erradicar el modelo express instalado desde la última licitación.

\section{Conclusión}

Al concluir este artículo espero haber justificado suficientemente que, el sistema de mediación familiar licitada que opera en nuestro país hace más de un lustro ha instalado en los dos últimos años un modelo de mediación de dudosa calidad que no logra plasmar debidamente el sistema de valores y principios que sirve de fundamento a esta disciplina. Y que, a causa de ello, se ven distorsionadas en gran medida la esencia y ventajas comparativas que ofrece esta instancia como mecanismo de intervención y abordaje de los conflictos familiares, conspirando en contra de ofrecer un servicio de excelencia que optimice el acceso a la justicia de la comunidad, pero por sobre todo que promueva el protagonismo y autodeterminación de las personas.

Sostengo responsablemente que, mientras la autoridad solo retribuya el trabajo de los mediadores licitados cuando la mediación concluya en acuerdo aprobado judicialmente -sin importar el número de sesiones, ni cómo o en cuánto tiempo se haya arribado al acuerdo- y, mientras esa retribución continúe siendo exigua, los prestadores contratados se verán compelidos a absorber un alto volumen de causas, persistiendo una práctica desprolija de la actividad mediadora que hemos denominado mediación express. De nada servirá una política de incentivos que no esté encaminada a contrarrestar estos males.

38 Moffit, Michael, obr. cit., p.213.

39 Una cuestión interesante de dilucidar es contra quién ha de dirigirse la demanda en el caso de la mediación familiar licitada en que es el Estado el que proporciona los servicios profesionales a la comunidad a través de las personas naturales y jurídicas adjudicatarias. ¿Se podría demandar directa o conjuntamente al Estado por falta de servicio? Evidentemente, se trata de un asunto demasiado complejo que excede las pretensiones de este artículo. 
Finalmente, concluyo planteando que el control de la calidad del ejercicio profesional de los mediadores no es de exclusiva responsabilidad de la autoridad. Por el contrario, los mecanismos que aseguren la excelencia de la profesión mediadora han de ser variados. Si verdaderamente se quiere elevar el estatus de la mediación proponemos como necesario alentar el diálogo y tender puentes entre entidades y actores públicos y privados vinculados a esta disciplina -usuarios, mediadores, autoridades, dirigentes y académicos- pues todas estas perspectivas son valiosas para ir definiendo cómo deben hacerse las cosas en mediación y qué prácticas resultan aceptables y cuáles no, para, enseguida, elaborar y validar instrumentos que permitan evaluar aspectos cualitativos de los procesos, posibilitando la fijación de estándares de calidad que apunten al fortalecimiento y excelencia de esta disciplina. La tarea, por cierto, es desafiante, pero a la vez, ineludible y urgente. 


\section{Bibliografía}

Álvarez, Gladis, D'Alessio, Damián y Amilodare, Ana María, Calidad en mediación, en Brandoni, Florencia (comp.), Hacia una mediación de calidad, Editorial Paidós, Argentina, 2011.

Alliende Luco, Leonor, Burgos Pizarro, Jorge, Correa Camus, Paula y Pérez Castillo, Sandra, El proceso de mediación, Editorial Jurídica de Chile, Chile, 2002.

Barcia Lehmann, Rodrigo, Lecciones de Derecho Civil. De la teoría de las obligaciones. Tomo III, Editorial Jurídica de Chile, 2010.

Baruch Bush, Robert, Folger, Joseph, La promesa de la mediación, Editorial Granica, S.A. Argentina, 2006.

Diccionario de la Lengua Española, Real Academia Española, vigésima segunda edición, 2001.

Diez, Francisco, TAPIA, Gachi, Herramientas para trabajar en mediación, Editorial Paidós, Argentina, 1999.

Moffit, Michael, Las cuatro formas de asegurar la calidad del mediador (y por qué ninguna funciona) en Brandoni, Florencia (comp.), Hacia una mediación de calidad, Editorial Paidós, Argentina, 2011.

Rosselot, Eduardo, Aseguramiento de la calidad profesional.: Un nuevo marco ético para el ejercicio de la medicina /en/ Revista Médica de Chile, [online]. 1999, vol.127, n.11.

SuAREs, Marinés, Mediando en sistemas familiares, Editorial Paidós, Argentina, 2002. 


\section{Páginas web consultadas}

Síntesis Calidad de Servicio de Mediación Licitado por el Ministerio de Justicia, [on line], [consultada el 14-09-2011], Disponible en la World Wide Web: http:// www.mediacionchile.cl/MinJusPubl/Upload/SPDocs/EST_6.pdf

Diagnóstico al Sistema Licitado de Mediación Familiar, [on line], [consultada el 1409-2011], Disponible en la World Wide Web: http://www.mediacionchile.cl/ MinJusPubl/Upload/SPDocs/EST_10.pdf

Aplicación y análisis encuesta de satisfacción de usuarios y usuarias del sistema de mediación familiar, [on line], [consultada el 14-09-2011], Disponible en la World Wide Web: http://www.mediacionchile.cl/MinJusPubl/Upload/SPDocs/ EST_13.pdf

Bases de Licitación Pública y sus anexos para la contratación de servicios de mediación familiar, [on line], [consultada el 26-09-2011], Disponible en la World Wide Web: http://www.mediacionchile.cl/MinJusPubl/Upload/SPDocs/DEC904. pdf

Convención sobre los Derechos del Niño, [on line], [consultada el 24-09-2011], Disponible en la World Wide Web: http://www2.ohchr.org/spanish/law/crc.htm

Disponible en la World Wide Web: http://www.colegiodemediadores.cl/muestra_nota. php?id=60, [on line], [consultada el 30-09-2011].

Disponible en la World Wide Web: http://www.colegiodemediadores.cl/muestra_nota. php?id=52, [on line], [consultada el 24-09-2011].

Bases de Licitación y sus anexos y el formato tipo de contrato para la contratación de servicios de mediación familiar, [on line], [consultada el 25-09-2011], Disponible en la World Wide Web: https://www.mediacionchile.cl/MinJusPubl/Sitio/ documentos/pdf/Bases_Mediacion_Res_188_29_de_agosto_de_2011.pdf

Registro Público de Sanciones, [on line], [consultado el 25-09-2011], Disponible en la World Wide Web: http://www.mediacionchile.cl/MinJusPubl/Upload/SPDocs/ Sanciones/Sanciones_al_05_09_2011.pdf

Disponible en la World Wide Web: http://www.colegiodemediadores.cl/muestra_nota. php?id=59, [on line], [consultada el 30-09-2011] 